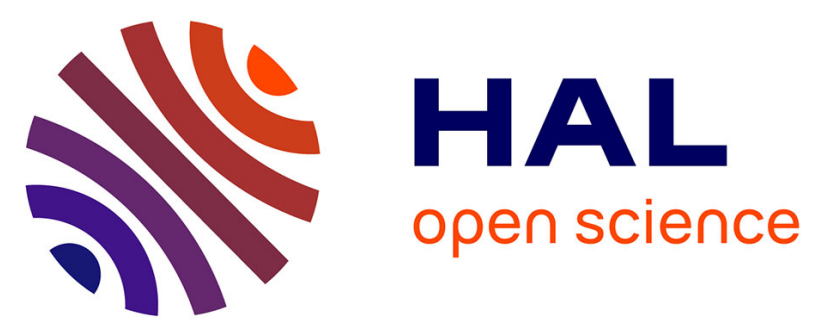

\title{
Improvement of the Bioactivity of UHMWPE by Two Different Atmospheric Plasma Treatments
}

S. Nejatbakhsh, Abdessakh Anagri, A. Valinataj Omran, Jérôme Pulpytel, Cyrille Bazin, M. Ullah, M. Mirshahi, H. Rezaie, J. Javadpour, Farzaneh Arefi-Khonsari

\section{To cite this version:}

S. Nejatbakhsh, Abdessakh Anagri, A. Valinataj Omran, Jérôme Pulpytel, Cyrille Bazin, et al.. Improvement of the Bioactivity of UHMWPE by Two Different Atmospheric Plasma Treatments. Plasma Chemistry and Plasma Processing, 2021, 41 (41), pp.245-264. 10.1007/s11090-020-10134-7 . hal03000662

\section{HAL Id: hal-03000662 https://hal.sorbonne-universite.fr/hal-03000662}

Submitted on 27 Jan 2021

HAL is a multi-disciplinary open access archive for the deposit and dissemination of scientific research documents, whether they are published or not. The documents may come from teaching and research institutions in France or abroad, or from public or private research centers.
L'archive ouverte pluridisciplinaire HAL, est destinée au dépôt et à la diffusion de documents scientifiques de niveau recherche, publiés ou non, émanant des établissements d'enseignement et de recherche français ou étrangers, des laboratoires publics ou privés. 
Article type: Full Paper

\section{'Declarations of interest: none'}

Title: Improvement of the Bioactivity of UHMWPE by two different Atmospheric Plasma treatments

S. Nejatbakhsh ${ }^{1}$, A. Anagri ${ }^{1}$, A. Valinataj Omran ${ }^{1}$, J. Pulpytel ${ }^{1}$, C. Bazin ${ }^{1}$, M. Ullah ${ }^{2}$, M. Mirshahi ${ }^{2}$, H. Rezaie ${ }^{3}$, J. Javadpour ${ }^{3}$, F Arefi-Khonsari $^{1^{*}}$

${ }^{1}$ Sorbonne Université, CNRS, Laboratoire Interfaces et Systèmes Electrochimiques, LISE, 75005 Paris, France

${ }^{2}$ Sorbonne Paris Cité, UMR Université Paris 7, INSERM U965 Carcinose, Angiogenèse et Recherche Translationnelle, L'Hôpital Lariboisière, 41 Bd de la Chapelle, 75010 Paris, France

${ }^{3}$ School of Metallurgy and Materials Engineering, Iran University of Science and Technology (IUST), Narmak, 16844 Tehran, Iran

e-mail: farzaneh.arefi@sorbonne-universite.fr

Keywords: DBD(dielectric barrier discharge); APPJ(Atmospheric Pressure Plasma Jet); Simulated Body Fluid(SBF); Hydroxyapatite(HA); Surface treatment; UHMWPE(ultrahigh molecular weight polyethylene) 


\begin{abstract}
Ultra-high-molecular-weight polyethylene (UHMWPE) has been treated by a helium/oxygen Dielectric Barrier Discharge as well as a rotative blown arc atmospheric pressure plasma jet (rAPPJ) in air to improve its bioactivity for total joint replacement implants as a biocompatible polymer. The latter was checked by increased adhesion of fibroblast cells to the polymer. The treated UHMWPE once immersed in a simulated body fluid (SBF) induced the formation of nucleus of hydroxyapatite (calcium phosphate) leading to the growth of a thick apatite coating, followed up to 14 days. Contrary to $\mathrm{DBD}$ treated polymer, the detection of $\mathrm{NO}_{2} / \mathrm{NO}_{3}$ groups besides the oxygen ones by XPS in the case of the APPJ treated UHMWPE, probably explains why the cell adhesion was not good on such surfaces.
\end{abstract}

\title{
Introduction
}

Ultra-high molecular-weight polyethylene (UHMWPE) is biocompatible but not bioactive, which limits its potential biomedical applications. Since UHMWPE is a hydrophobic polymer, characterized by non-polar moieties, it does not possess functional groups on the surface to favor attachment of any coating (e.g. apatite layer) which therefore leads to a low chemical reactivity and poor bioactivity. Therefore increasing the number of polar groups on the surface of UHMWPE, is intrinsic to enhance its bioactivity and bone bonding ability. [1] [2].

Starting in the 1970s, several surface treatment methods such as chemical, physical, thermal surface modifications, as well as coatings and some biomimetic methods were employed to render UHMWPE bioactive. Among the different surface modification methods used in the case of UHMWPE, plasma treatment is one of the most effective one. Plasma modification can easily introduce polarizable groups on the surface of materials using different reaction gases which 
result in improving surface hydrophilicity and roughness for enhanced wetting, dyeing, printing and adhesion properties to other coatings [3-9] .Atmospheric pressure plasma is a beneficial technology due to its versatility, low-cost, ability to produce reactive chemistry at room temperature and flexibility in terms of its operation and integration for in-line processing.

Depending on the energy, chemistry and the reactivity of the plasma-created species, different modifications can take place, e.g. functionalization, degradation, and crosslinking [10]. The main reactions occurring at the surface of polymers in $\mathrm{O}_{2}$, air, or $\mathrm{NO}_{2}$ plasmas are oxidizing ones, leading to functionalization with oxygen moieties onto the surface, while plasmas in noble gases apart from post-oxidation of free radicals created during the plasma treatment, will mainly produce cross-linking of polymer layers on the surface. Helium with its low degradation effect due to its low momentum, low breakdown voltage at atmospheric pressure and its high energy metastables, allows to obtain a homogeneous glow discharge at atmospheric pressure, which has been intensively used for the treatment of UHMWPE [5, 11-17]for improving its wear resistance and adhesion characteristics. According to the literature, the addition of $1 \%$ of $\mathrm{O}_{2}$ to helium in a DBD reactor improves the hydrophilicity of polymer surfaces due to the introduction of oxygen bearing groups such as hydroxyl, carbonyl and carboxylic groups [12][18].

Since 1990 Simulated Body Fluids (SBF) has been used for in vitro study of bioactivity of biomaterials which can be described by hydroxyapatite precipitation on the surface of different types of biomaterials.[19-24]. As mentioned before, because of its chemical inertness, UHMWPE, a hydrophobic polymer, should undergo surface modifications which will introduce polar heteroatoms on the surface. These moieties will act as active sites for apatite nucleation.[16]The apatite nucleation time on polyethylene surface is usually from one to 3 days for most of the polymers reported in the literature and give rise to a thick apatite layer after 15 to 30 days of immersion in SBF [19] [20]. So faster nucleation, larger crystals, and stronger bonding of the bioactive Ca-P layer on the orthopedic material surface is considered as better bioactivity. [2526].

Literature shows that pre-treatment of the surface of UHMWPE with wet processes with $\mathrm{NaOH}$ improves the formation of potential apatite nuclei on UHMWPE surface from SBF solution.[27] 
More recent studies have reported a successful result on bioactivity improvement of UHMWPE by using plasma technologies. In these studies plasma polymerization of methyl methacrylate (MMA) in a dielectric barrier discharge (DBD)-reactor using helium gas was performed to alter the surface chemistry and inertness of UHMWPE samples[13][14].

On the other hand, besides the biological performance of the biomaterials, to ensure that the surface of the treated samples would not induce adverse response from the body, the biocompability of the polymer after surface modification has to be analyzed in terms of the potential toxicity and detrimental effects in the physiological environment. Cell adhesion and proliferation tests are often used to assess the viability of cells on a surface.

It has been reported in the literature that the enhanced surface free energy induced by the $\mathrm{He} / \mathrm{O}_{2}$ cold atmospheric pressure plasma treatments, can lead to a significant effect on cell adhesion and HFF-1cells (humanforeskinfibroblasts,ATCC) cell proliferation. The cells were more evenly spread on the plasma pretreated samples and predominantly showed an elongated, spindle-like shape with only a few visible dead cells[6, 29] [12].

Also UHMWPE surfaces exposed to an argon plasma showed positive response to the adhesion and proliferation of vascular smooth muscle cells (VSMCs) and connective tissue cells L929[30] In this work, the effect of surface modification of ultra-high-molecular-weight polyethylene (UHMWPE), by atmospheric discharges on deposition of hydroxyapatite (HA) from simulated body fluid (SBF), was investigated. The study will focus on comparison of the effect of the surface treatment of UHMWP by two discharges namely Dielectric Barrier Discharge (DBD) using a $\mathrm{He} / \mathrm{O}_{2}$ mixture and a rotary arc blown (Atmospheric Pressure Plasma Jet) APPJ in air. The surface modifications were investigated by ATR-FTIR, XPS, TF-Xray, AFM, SEM and the wettability and the ageing of the surface properties by water contact angle (WCA) measurements. Furthermore, to access the in vitro bioactivity, the deposition of hydroxyapatite (HA) from simulated body fluid (SBF) as well as the interaction and adhesion of fibroblast cells on the plasma-treated surfaces were studied.

\section{1- Materials and methods}

UHMWPE film with a thickness of $0.075 \mathrm{~mm}$ was provided by Goodfellow, UK. 


\subsection{Dielectric barrier discharge setup and characterization}

A schematic of the plasma reactors are shown in Figure 1.

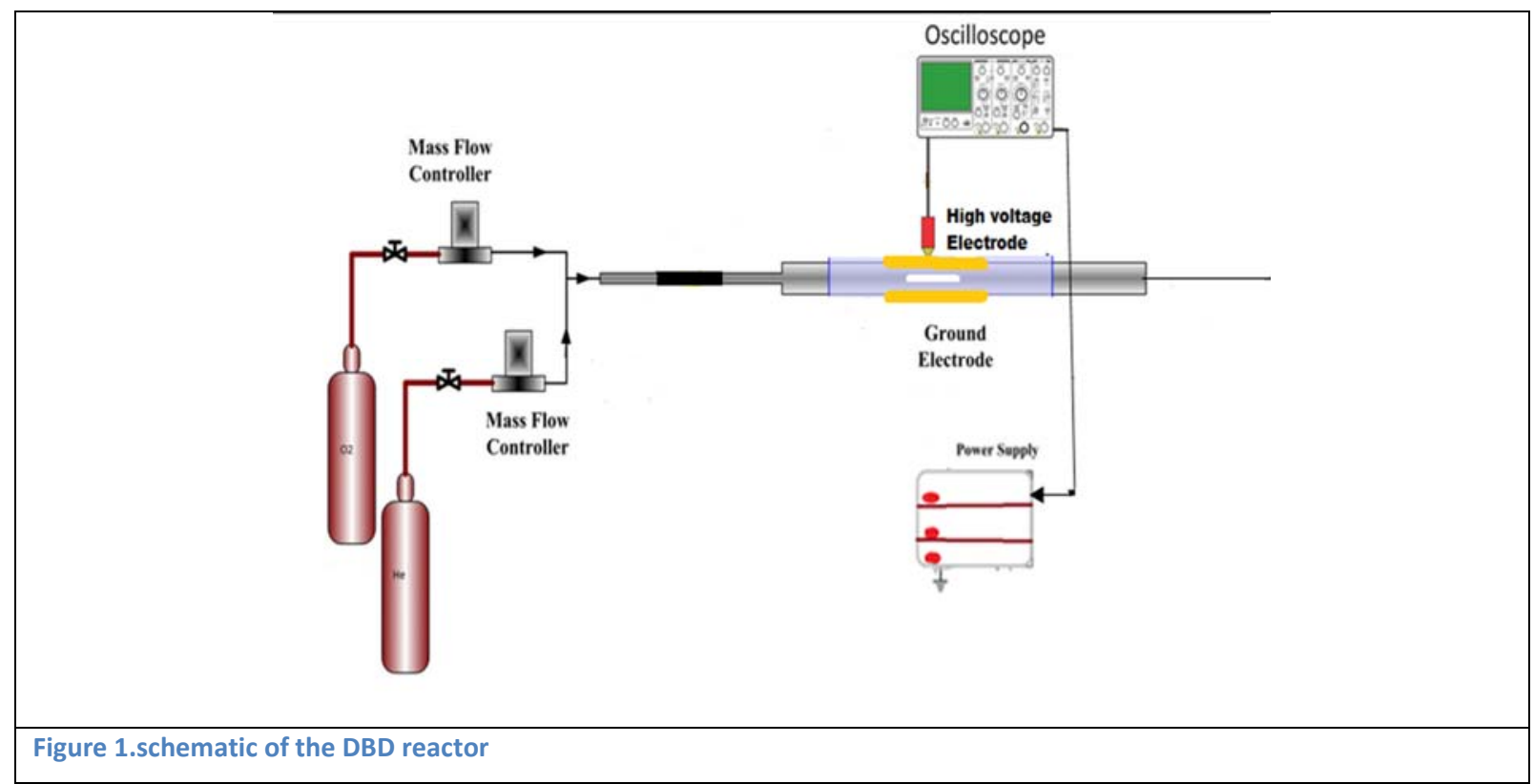

A symmetrical DBD was generated between 2 copper electrodes $(28 * 28 \mathrm{~mm})$ adhered to two glass plates $(80 * 46 * 8 \mathrm{~mm})$. The inter-electrode distance was $2 \mathrm{~mm}$. The lower electrode was grounded, while the upper electrode was connected to a AC high voltage power source at a frequency of 44 $\mathrm{kHz}$. The UHMWPE samples were fixed on the lower glass plate, and the power delivered by the generator was calculated by measuring the voltage(kV) by a HV probe (HV GE 3830 probe) and the current $(\mathrm{mA})$ by a wideband current probe (Pearson Electronics, Inc., model 3972 ). The timeaveraged electrical power consumed by the plasma DBD reactor can be calculated by equation (1) where $v(t)$ and $i(t)$ are, respectively the voltage and the current versus time, $T$ is the waveform period:

$$
P=\frac{1}{T} \int_{t=0}^{T} v(\boldsymbol{t}) \times i(\boldsymbol{t}) d t
$$

Fig. 2 shows a typical voltage-current plot obtained in a $\mathrm{He}$ and $2 \% \mathrm{O}_{2}$ discharge. The power calculated in pure helium was $3.77 \mathrm{~W}$ which increased slightly to $3.86 \mathrm{~W}$ with $2 \%$ of $\mathrm{O}_{2}$ in different 
flow rates of $\mathrm{He}$, showing that the power dissipated in the discharge was approximately constant during all experiments.

As shown in the fig 2, the applied voltage is sinusoidal while the signature of the measured current confirms the stability and the homogeneity of the discharge by the presence of two current peaks for each applied voltage periods[30,31]. An approximate value of power density of $3.9 \mathrm{~W} / \mathrm{cm}^{2} \mathrm{can}$ be calculated taking into consideration the dimensions of the electrode and the inter-electrode distance. The power density being very low in the DBD discharge in He and mixtures of $\mathrm{He}+2 \%$ $\mathrm{O} 2$, the gas and the substrate temperature were both at ambient temperature. The flowrates of $\mathrm{He}$ and $\mathrm{O} 2$ were the following: He flow rate $=0.5 \mathrm{slm}+10 \mathrm{sccm}\left(\mathrm{He}+2 \% \mathrm{O}_{2}\right)$.

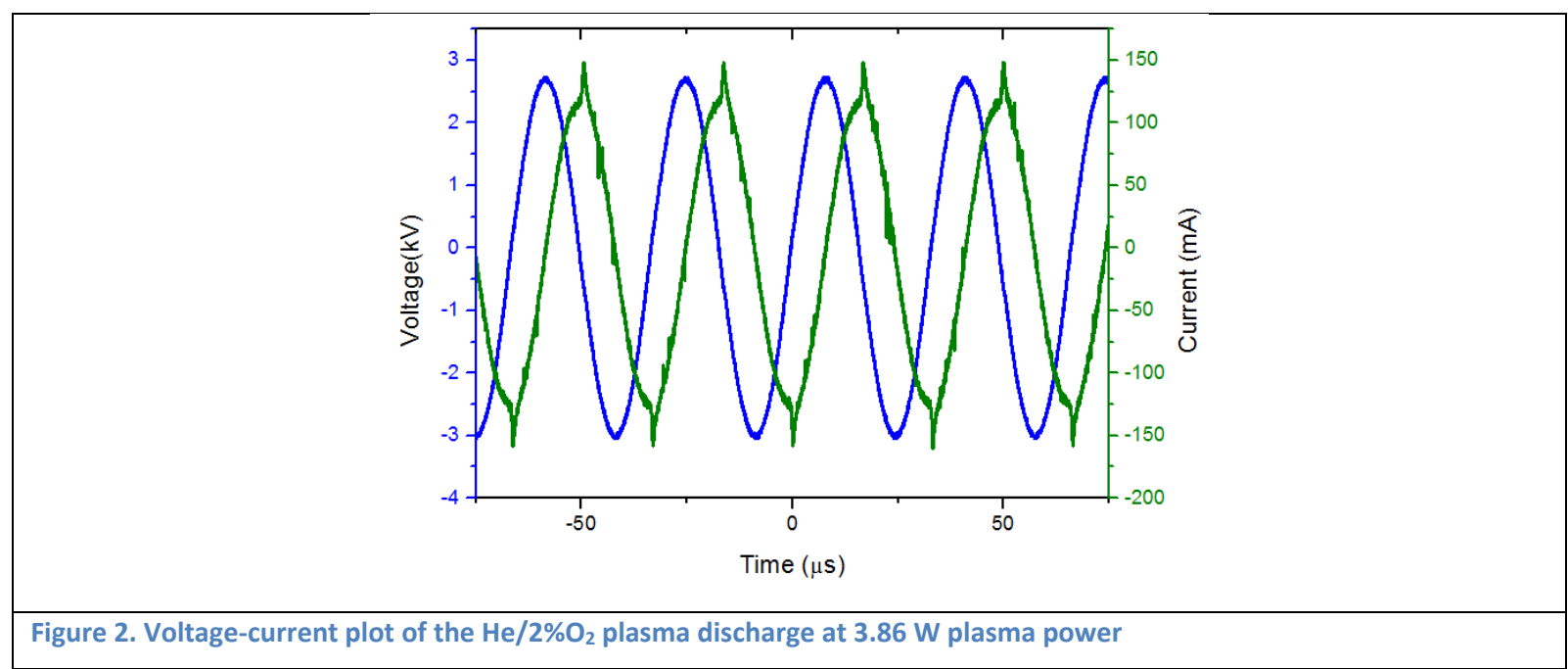

\subsection{Atmospheric Pressure Plasma Jet set-up and characterization}

Figure 3 shows the schematic of the atmospheric pressure jet used for UHMWPE activation 


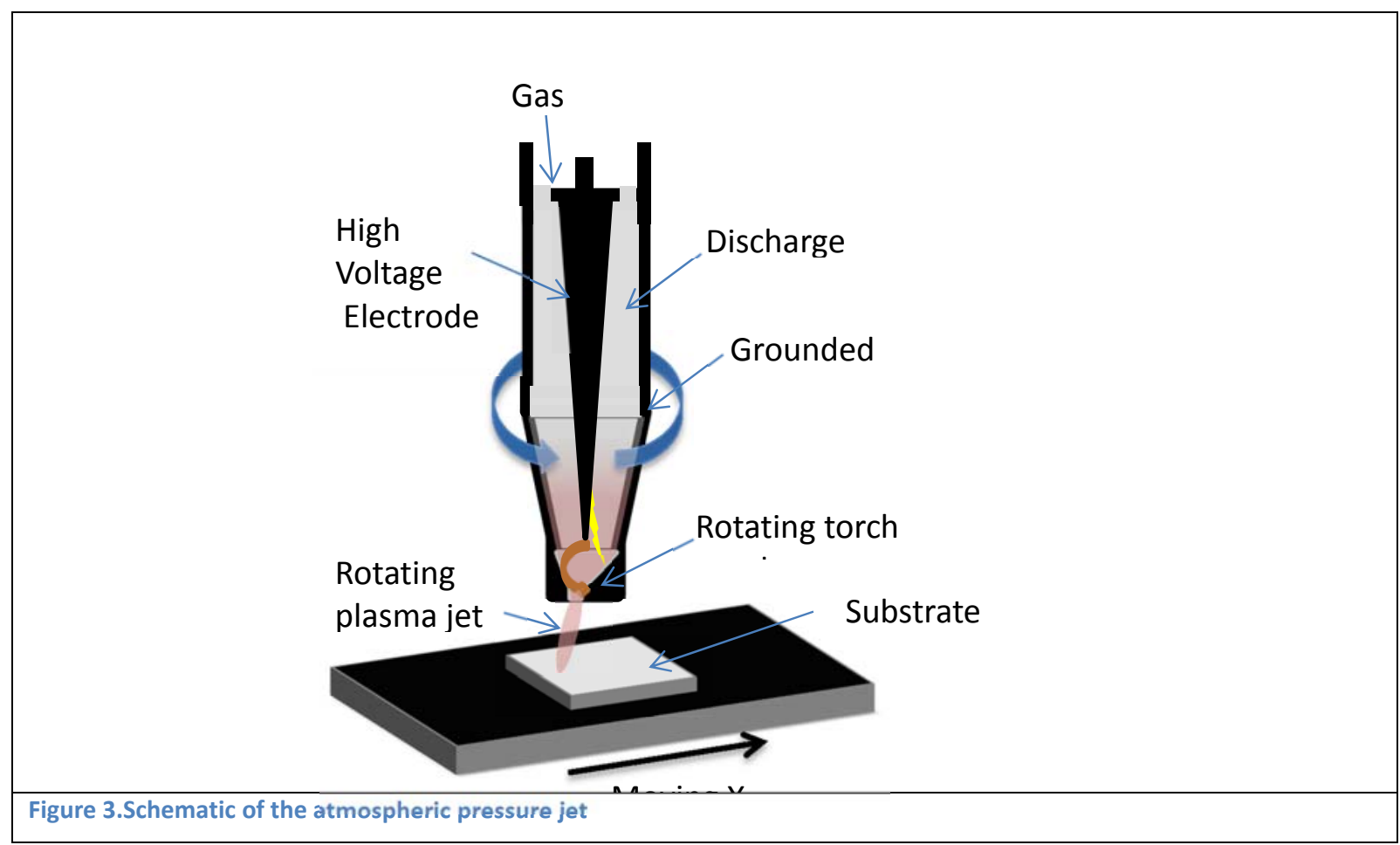

The surface treatment of UHMWPE was carried out with a non- equilibrium APPJ Openair FG 5001 equipment (Plasmatreat GmbH, Steinhagen, Germany) working in a pulsed mode and using compressed air as the plasma gas. A rotating nozzle with an opening ring of $4 \mathrm{~mm}$, a rotation speed of $2900 \mathrm{t} \mathrm{min}-{ }^{1}$ and effluent angle of $14^{\circ}$ was used.

The atmospheric plasma jet was placed over a movable platform on which the UHMWPE was fixed, and it could be moved across the air plasma under controlled speed from 5 to $50 \mathrm{~m} \cdot \mathrm{min}^{-1}$. The plasma jet was fixed to a movable arm, the position of which could be varied vertically, and thus the distance between the plasma jet head and the platform could be varied between 10 and $100 \mathrm{~mm}$. The voltage and the pulse frequency of the plasma source could be modulated from 270 to $300 \mathrm{~V}$ and from 19 to $23 \mathrm{kHz}$, respectively. Since the plasma source works in a pulsed mode, the pulsed power-cycle time (PCT) could be changed between 50 and 100\%, which represented the ratio of the ton/toff * 100 . This pulsed operating mode allows the plasma jet, which is a blown DC arc plasma, to achieve non-equilibrium plasma conditions. The plasma conditions used were fixed for this study and were the following: Nozzle-distance $=10 \mathrm{~mm} ; f=21 \mathrm{kHz}$, speed; $15 \mathrm{~m} / \mathrm{min}$; $\mathrm{PCT}=80 \%$; number of scans $=2$ to 7. In these conditions the gas temperature at a distance of 10 
$\mathrm{mm}$ from the nozzle was 500K [36]. The power was a round $400 \mathrm{~W}$, knowing that the plasma on the surface is the size of a doughnut of $5 \mathrm{~cm}$ of diameter and $1 \mathrm{~cm}$ of thickness, the power density is around $57 \mathrm{~W} / \mathrm{cm}^{2}$, which is much higher than the case of the DBD system as mentioned above. However, the temperature drops down very quickly from the nozzle to the surface of the polymer, and measurements carried out with the help of an Infrared camera show a surface temperature of UHMWPE which varies between 40 and $50^{\circ} \mathrm{C}$ for 2 to 7 scans.

After the treatment, the films were immediately placed in a clean plastic container which was then sealed to minimize potential contamination.

\subsection{Preparation of polymer substrates}

In order to improve the bioactivity of UHMWPE, plasma surface modifications by the two atmospheric discharges (APPJ and DBD) were carried out. Then to determine the bioactivity improvement as well as the biocompatibility of the UHMPW surfaces, the plasma-treated polymer films were immersed in simulated body fluid (SBF) as well as fibroblast cells in a DMEM medium.

The UHMWPE film was cut in $2 * 2 \mathrm{~cm}^{2}$ samples. Prior to each plasma treatment, the samples were cleaned in ethanol for 5 min to remove the contaminants from the surfaces and then were dried in air and fixed on the grounded electrode by using a double-sided tape. Two different setups, shown in Figure 1 and 3 were used to obtain the best conditions for surface modification and functionalization.

\subsection{Simulated body fluid (SBF)}

Simulated body fluid with an ion concentration similar to those of human blood plasma, developed by Kokubo [19] was prepared. The following ACS reagents supplied by SigmAldrich in France: $\mathrm{NaCl}, \mathrm{NaHCO}, \mathrm{KCl}, \mathrm{K}_{2} \mathrm{HPO}_{4} .3 \mathrm{H}_{2} \mathrm{O}, \mathrm{MgCl}_{2} .6 \mathrm{H}_{2} \mathrm{O}, \mathrm{CaCl}_{2}, \mathrm{Na}_{2} \mathrm{SO}_{4}$ and Tri-hydroxymethyl aminomethane $\left(\mathrm{H}_{2} \mathrm{NC}\left(\mathrm{CH}_{2} \mathrm{OH}\right)_{3}\right)$ were dissolved in $750 \mathrm{~mL}$ of ultra purified water and buffered with $1 \mathrm{M} \mathrm{HCl}$ to $\mathrm{pH} 7.40$ at $37{ }^{\circ} \mathrm{C}$. It was necessary to take special care to dissolve each reagent before adding the other reagents. Then the total volume of the solution was adjusted to $1000 \mathrm{~mL}$. Once the SBF solution prepared, it was stored at $4^{\circ} \mathrm{C}$ and could be used up to one month. 
After substrate pretreatment, samples were soaked vertically in the SBF and incubated at $37{ }^{\circ} \mathrm{C}$ for $1,3,7,14$ and 30 days. Deposition took place in sterile tubes filled with approximately $25 \mathrm{ml}$ of SBF, while the samples were held in a vertical position. SBF immersion lasted for $3,7,14,30$ days with daily solution refreshments. Solution refreshments were performed by pipetting the old solution from the container and gently pouring in fresh solution, so as to not disturb the samples. On the final day of immersion, samples were removed from the SBF, rinsed with deionized water and allowed to dry in the oven at $37^{\circ} \mathrm{C}$.

\subsection{Biocompatibility and cell adhesion test}

The cellular interactions of the plasma activated samples were examined as follows: primary human fibroblast cells were cultured in DMEM medium (purchased from Sigma Aldrich; added with $4 \% \mathrm{FBS}, 1 \% \mathrm{P} / \mathrm{S}$ ) and were harvested using trypsin and then washed with the DMEM medium. Cells were counted using C-chip Haemocytometer (Lab-tech) and were cultured with treated and non treated UHMWPE samples placed in 6-well PS plates. 100,000 cells with $2.5 \mathrm{ml}$ of DMEM medium was placed in each well and evaluated after $24,48,72 \mathrm{~h}$ with SEM and optical microscope.

\subsection{Surface analytical techniques}

\section{a) Static contact angle}

Wettability changes of the treated UHMWPE surfaces were characterized by static contact angle measurements using the sessile drop technique measured with a GBX tensiometer using a CCD camera and a horizontal light source to illuminate the liquid droplet $(V=6 \mu l) .3$ measurements per sample and 3 samples per same plasma condition were used i.e. each static WCA value was the mean of 9 acquisitions.

\section{b) ATR-FTIR}

Chemical structures of treated and nontreated UHMWPE samples were characterized using a Bruker VERTEX 70 FT-IR Spectrophotometer equipped with a single reflection ATR accessory using a germanium crystal as an internal reflection element. Infrared absorbance spectra were recorded in the $400-4000 \mathrm{~cm}^{-1}$ range, with a resolution of $4 \mathrm{~cm}^{-1}$. The signal of the bare substrate 
was taken as reference before each scan. Baseline corrections were then performed by OPUS 6.5 software after 200 scans of each sample.

\section{c) SEM}

The morphology of UHMWPE films was studied by Field Emission Scanning Electron Microscopy (FE-SEM). FE-SEM images were taken using Zeiss Ultra 55 FEG SEM with GEMINI Column on gold coated surfaces by sputter coating (Cressinton sputter coater-108 auto).

\section{d) AFM}

An atomic force microscope (AIST-NT SmartSPM 1000, AIST-NT, USA) operating in the AC mode was used to examine the topography and roughness of the films. The AIST-NT Control software was used to generate the AFM images. The Plane Level function in the software was applied to all AFM images.

e) XPS

XPS surface analysis of the UHMWPE samples was performed on a XPS (Axis Ultra, Kratos, UK) equipped with a monochromatic aluminium Ka X-ray source (1486.6 eV). Casa XPS fitting software was used to curve fit the high resolution C1s peaks. The hydrocarbon component of the C1s spectrum (285.0 eV) was used to calibrate the energy scale. In a next step, the peaks were deconvoluted using the Gaussian curve-fitting technique.

\section{f)X ray diffraction (XRD)}

XRD (Scintag XDS 2000 Diffractometer) was employed to investigate the structure of the modified UHMWPE surface and the composition of the HA films deposited on the different plasma treated UHMWPE samples and SBF treated samples for 14 days were subjected to a $16 \mathrm{~h}$ XRD scan utilizing $\mathrm{Cu} \mathrm{K} \alpha$ radiation $\left(\mathrm{k}=1.54 \mathrm{~A}^{\circ}\right)$. A Bragg-Brentano diffractometer was used in the $\Theta-2 \theta$ configuration.

\section{2- $\quad$ Results and Discussion}

\subsection{Surface modification of the UHMWPE film}




\section{a) Water Contact Angle measurements (WCA)and ageing of the surface properties}

First of all the surface modification of UHMWPE was studied by contact angle measurements which showed in both discharges used i.e. APPJ in air and DBD discharge in a mixture of 0,5 s/m $\mathrm{He}+10 \mathrm{sccm}$ oxygen gas that the surface energy of UHMWPE was substantially increased. The WCA of the control sample (WCA: $109^{\circ}$ ) decreased with increasing plasma treatment time in the DBD reactor or number of scans performed by the APPJ in air. The more the number of scans, the lower the WCA obtained until a plateau value of approximately $44^{\circ}$ was reached, while the minimum CA values obtained by prolonging the $D B D$ treatment time was about $55^{\circ}$ for a treatment time of 5 minutes in a mixture of $\mathrm{He}+\mathrm{O} 2$.These measurements along with the ageing of the CA measurements are shown in Figure 4.

Indeed one of the problems that hinder the application of plasmas in surface modification of polymeric materials is the potential aging of the treatment effects. After plasma treatments, the polymer surfaces show a gradual hydrophobic recovery over time surface free energy simultaneously decreases mainly due to two mechanisms: one is the re- orientation of polar chemical groups on the treated surface towards the bulk of the material, and the other is the diffusion of portions of non-modified macromolecules or hydrophobic additives to the surface[31-33]. The extent of hydrophobic recovery in the case of the DBD-treated UHMWPE is $9 \%$ after 14 days of ageing, while for the APPJ it is much higher (38\%). This difference has been explained by the fact that helium metastables and VUV in a helium discharge play an important role in crosslinking the surface and therefore reinforcing the topmost layer of the polymer surface, therefore limiting the hydrophobic recovery (9\%). As compared to the literature [22] the contact angles of UHMWPE increased from $63^{\circ}$ to $86^{\circ}$ for pure helium discharge and from $61^{\circ}$ to $78^{\circ}$ for helium $+1 \% \mathrm{O} 2$ plasma mixture, and from $68^{\circ}$ to $102^{\circ}$ for helium $+2 \% 02$ mixtures. Also the ageing of Ar plasma modified UHMWPE polymers, was studied by Reznickova et al. [30] who showed that the plasma treated polymer film for $480 \mathrm{~s}$ in (Ar) went through ageing and the WCA increased from $20^{\circ}$ to $120^{\circ}$ after $100 \mathrm{~h}$.

\section{b) Study of the ageing of the APPJ and DBD treated polymer surfaces}




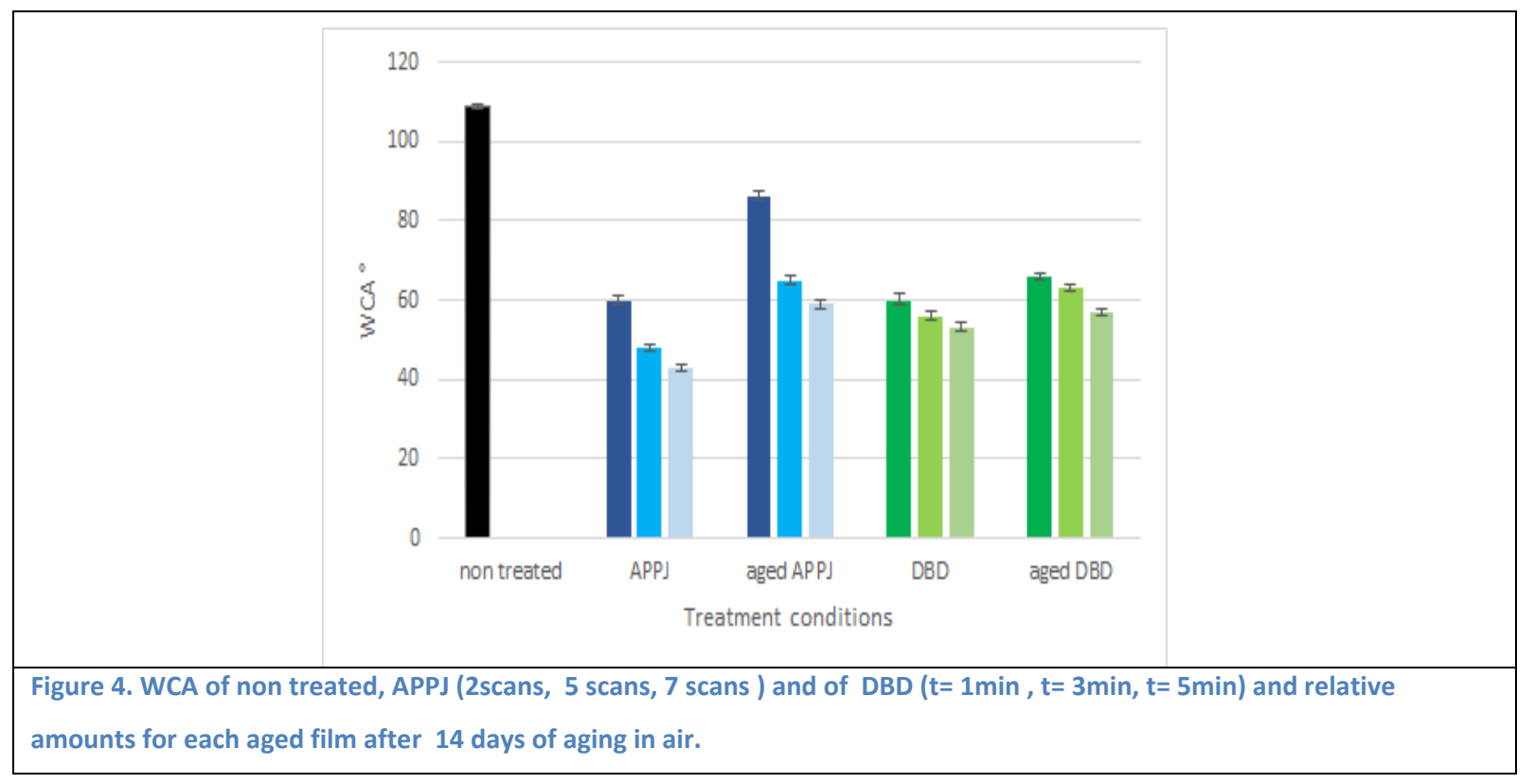

Based on these results, the optimum treatment conditions of each reactor were chosen to further investigate the plasma-induced effects on the surface chemistry and functional groups, HA deposition and cell proliferation studies. The best APPJ treatment conditions were $15 \mathrm{~m} / \mathrm{min}, 80 \% \mathrm{PCT}, 21 \mathrm{kHz}$, and a nozzle-substrate distance of $10 \mathrm{~mm}$ and 5 scans. As for the DBD discharge the best conditions were optimized for a mixture of $50 \mathrm{~s} / \mathrm{m} \mathrm{He}$ and $10 \mathrm{sccm}$ of Oxygen with a measured power $=3.86$ $\mathrm{W}$ and a treatment time $=5 \mathrm{~min}$.

\section{2-2 FTIR measurements}

Fig. 5 shows the FTIR spectra of the non-treated, APPJ treated (a) , DBD treated (b) UHMWPE. The absorption peaks identified at $2917,2848,1467$, and $722 \mathrm{~cm}-1$ are attributed to methylene nonsymmetrical stretch vibrations, methylene symmetrical stretch vibration, methylene nonsymmetrical variable angle vibration, and methylene swing in plane vibration, respectively. When the treated UHMWPE spectrum is compared to the spectrum of the untreated films, one can identify a broad band around $1500-1747 \mathrm{~cm}-1$ which appears due to the plasma treatment, which corresponds to $\mathrm{C}=\mathrm{C}$ groups at $1637 \mathrm{~cm}^{-1}$. The latter indicates unsaturation in the polymer 
backbone, a synergic reaction which usually takes place with cross-linking of the polymer. Furthermore $\mathrm{C}=\mathrm{O}$ in ketones and lactones (cyclic ester groups) are observed at $1732 \mathrm{~cm}^{-1}$.

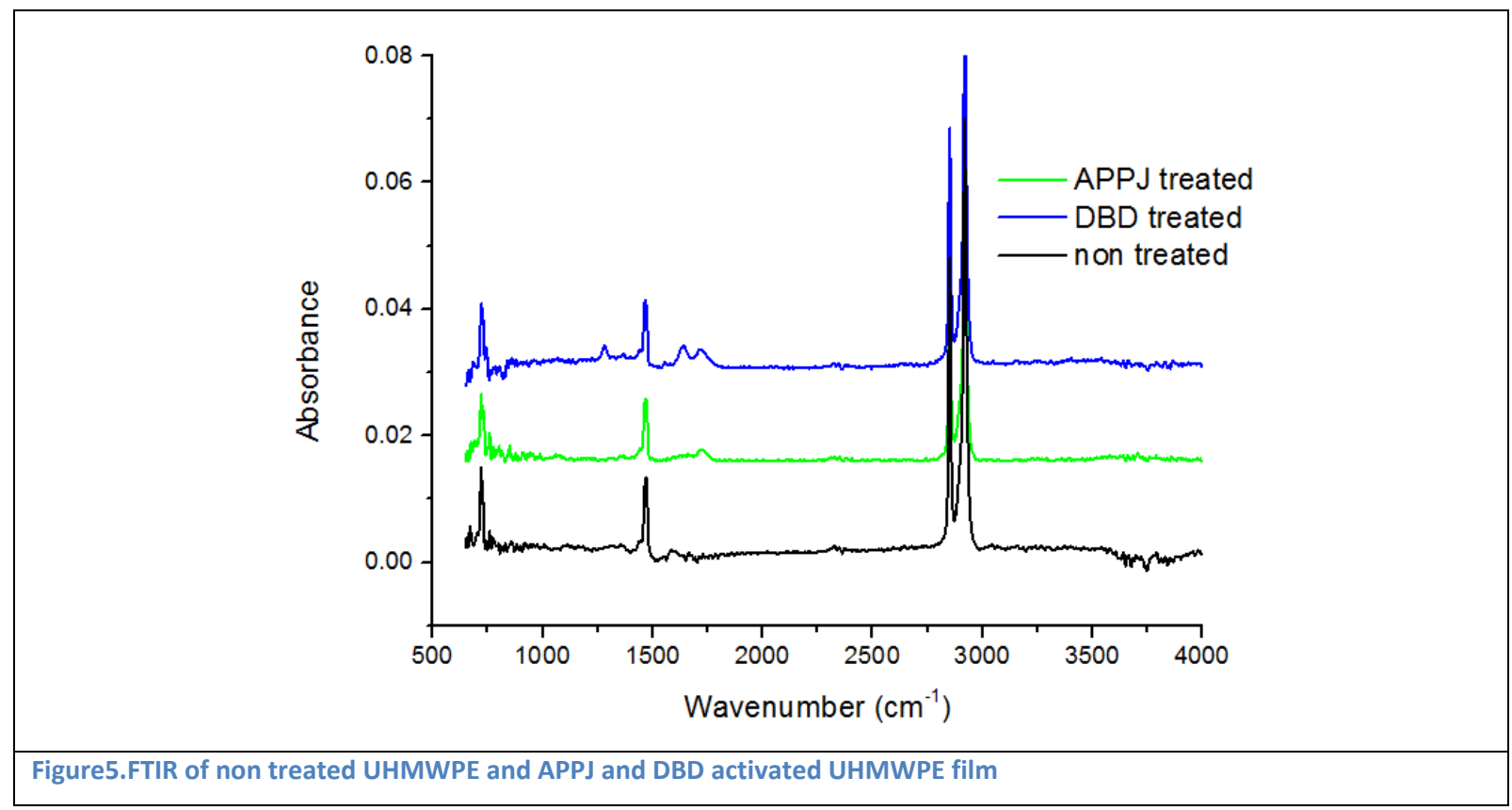

As shown is Figure 5, one can note that the absorption peak areas, which correspond to the vibrational strength of different chemical groups, are broader and less intense in FTIR spectra of treated UHMWPE samples, as compared to the untreated ones. This can be related to crosslinking of molecular chains that hinder the stretch vibration indicating an increased crosslinking density of UHMWPE chains after plasma activation by both methods.

In order to better investigate the spectral region ranging from 1550 to $1800 \mathrm{~cm}^{-1}$, the envelope has been deconvoluted by fitting Gaussian peaks shown in Figure 6 and their corresponding attributions have been given in Table 2 . 


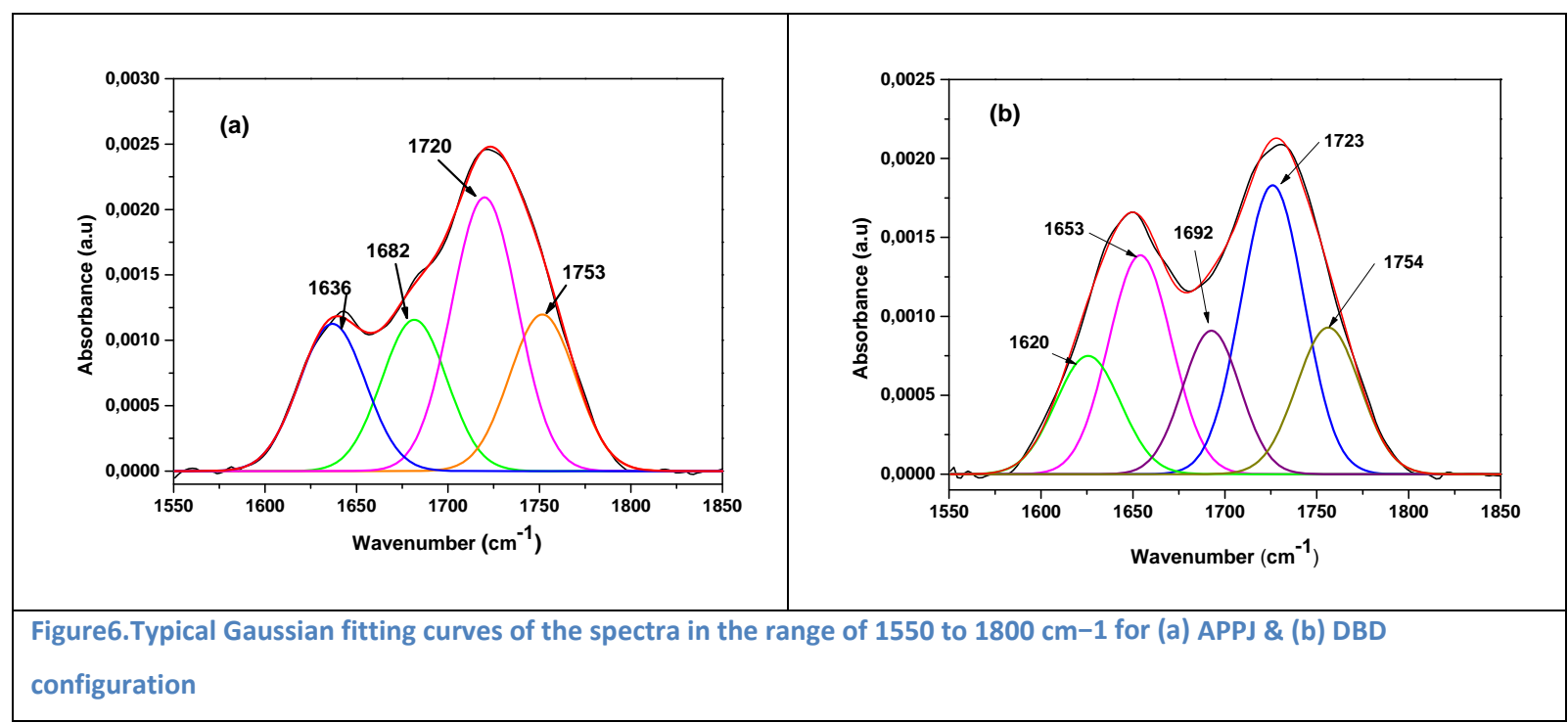

Table 2. Characterization of Gaussian fitting curves of a typical FTIR spectrum in the range of 1550 to $1800 \mathrm{~cm}-1$.

Wavenumber $\left(\mathrm{cm}^{-1}\right)$

1600

$1628,1637,1654,1663,1673$

$1700,1720,172$

$1737,1750,1770$

\section{Vibrational mode}

aromatics $\mathrm{C}=\mathrm{C}$ stretching

alkenes $\mathrm{C}=\mathrm{C}$ stretching/ amide

ketone $\mathrm{C}=\mathrm{O}$ stretching $/ \mathrm{C}=\mathrm{O}$ stretching in

amide groups

ester $\mathrm{C}=\mathrm{O}$ stretching

From these results it is obvious that first of all both activation methods led to incorporation of oxygen-containing functional groups which can act as the apatite nucleation sites on the surface once the polymer is immersed in SBF. Secondly the envelope observed ranging from 1550 to 1800 $\mathrm{cm}^{-1}$, is broader in the case of the DBD-treated UHMWPE as compared to the APPJ-treated one, showing evidence of a more crosslinked structure in the case of the former. This is the reason why we can deconvolute it into 5 peaks as compared to the APPJ one (4 peaks).

\subsection{XPS spectroscopy}

XPS was used to obtain a better evidence of different chemical moieties on the surface as well as 
to determine an overall semi-quantitative stoichiometry of the the topmost layer $(<8 \mathrm{~nm})$. The results support the ATR- FTIR measurements given above. Figure 6 shows the XPS spectra acquired for the non treated, APPJ and DBD treated UHMWPE film. As shown in the figure7 (C1s photoelectron peaks) has been decomposed into 4 photoelectron peaks centered at $285 \mathrm{eV}$; $285.9 \mathrm{eV} ; 287.6 \mathrm{eV}$ and $289.7 \mathrm{eV}$ which has been attributed to (C-C); (C-O/C-OH); (C=O) and O$\mathrm{C}=\mathrm{O}$ Respectively. One can note that more oxygen moieties (cf Table 3 ) and in particularly $(\mathrm{COOH} / \mathrm{COOR})$, groups are detected on DBD-treated surface. By deconvoluting the N1s photoelectron peak, besides amine/amide functional groups identified on both DBD and APPJ treated polymer, NO2/NO3 moieties were detected on APPJ-treated surface. Indeed optical emission spectra of the blown arc, air plasma jet is dominated by a broad continuum centered at $630 \mathrm{~nm}$ attributed to the chemiluminescence of NO2 species [37], which will then be ease grafted to the surface of the plasma activated UHMWPE.

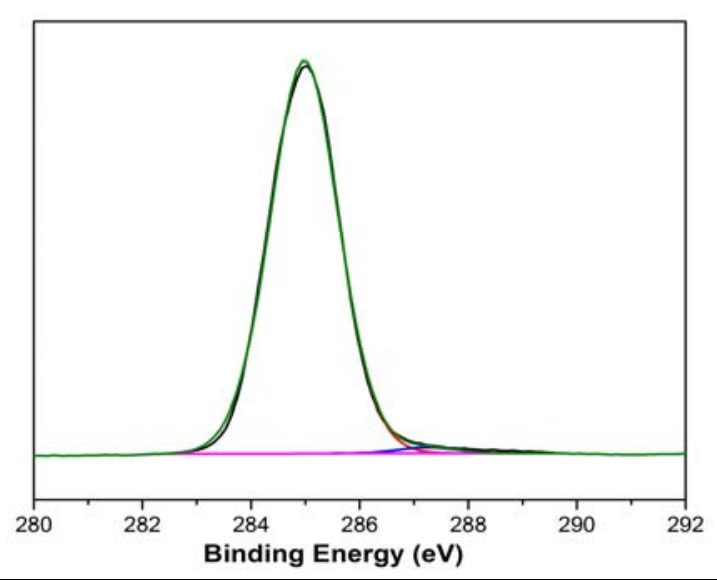




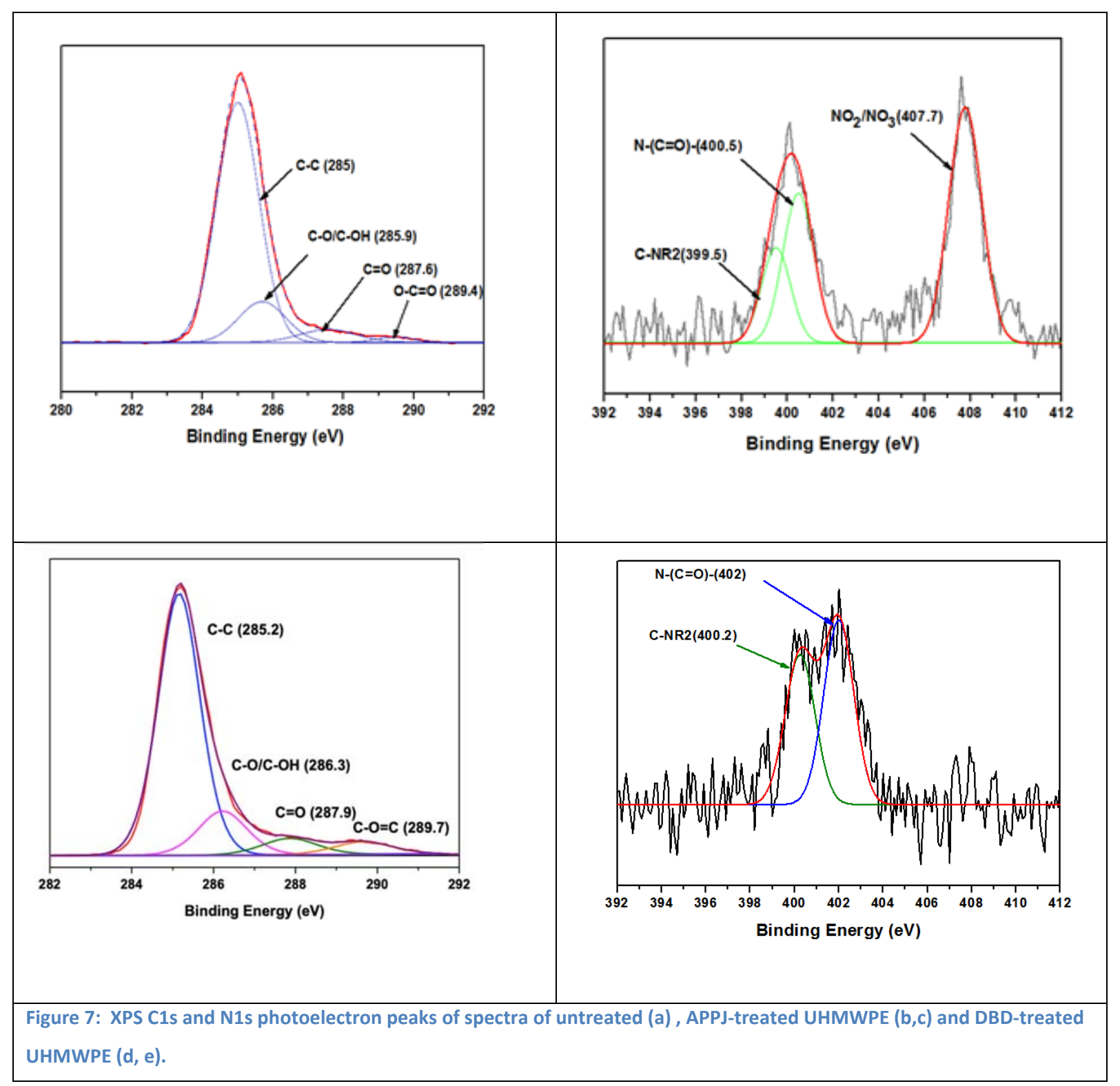

Table 3. Elemental composition and peak deconvolution of C1s and N1s for the UHMWPE film surfaces

\begin{tabular}{|l|l|l|l|l|l|l|l|l|l|l|}
\hline & \multicolumn{3}{|l|}{$\begin{array}{l}\text { Atomic } \\
\text { composition (\%) }\end{array}$} & \multicolumn{4}{l|}{ C1s peak deconvolution (\%) } & \multicolumn{2}{l|}{$\begin{array}{l}\text { N1s peak deconvolution } \\
(\%)\end{array}$} \\
\hline Sample & $\mathrm{C}$ & $\mathrm{O}$ & $\mathrm{N}$ & $\mathrm{C}-\mathrm{C}$ & $\mathrm{C}-\mathrm{O}(\mathrm{H})$ & $\mathrm{C}=\mathrm{O}$ & $\mathrm{O}-\mathrm{C}=\mathrm{O}$ & $\mathrm{C}-\mathrm{NR} 2$ & $\mathrm{~N}-\mathrm{C}=\mathrm{O}$ & $\begin{array}{l}\text { NO2/ } \\
\text { NO3 }\end{array}$ \\
\hline $\begin{array}{l}\text { Non } \\
\text { treated }\end{array}$ & 97.4 & 2.6 & 0 & 98.76 & 1.24 & 0 & 0 & 0 & 0 & 0 \\
\hline
\end{tabular}




\begin{tabular}{|l|l|l|l|l|l|l|l|l|l|l|}
\hline APPJ & 91.0 & 7.8 & 1.2 & 78.17 & 14.75 & 5.55 & 1.53 & 18,26 & 30,54 & 51,20 \\
\hline DBD & 85.3 & 14.3 & 0.4 & 76.12 & 10.56 & 6.71 & 6.61 & 44,81 & 55,19 & 0 \\
\hline
\end{tabular}

\subsection{AFM measurements}

AFM analysis was carried out to study the roughness and morphological changes produced by plasma treatment on the polymer surfaces. Figure 8 shows the AFM images.

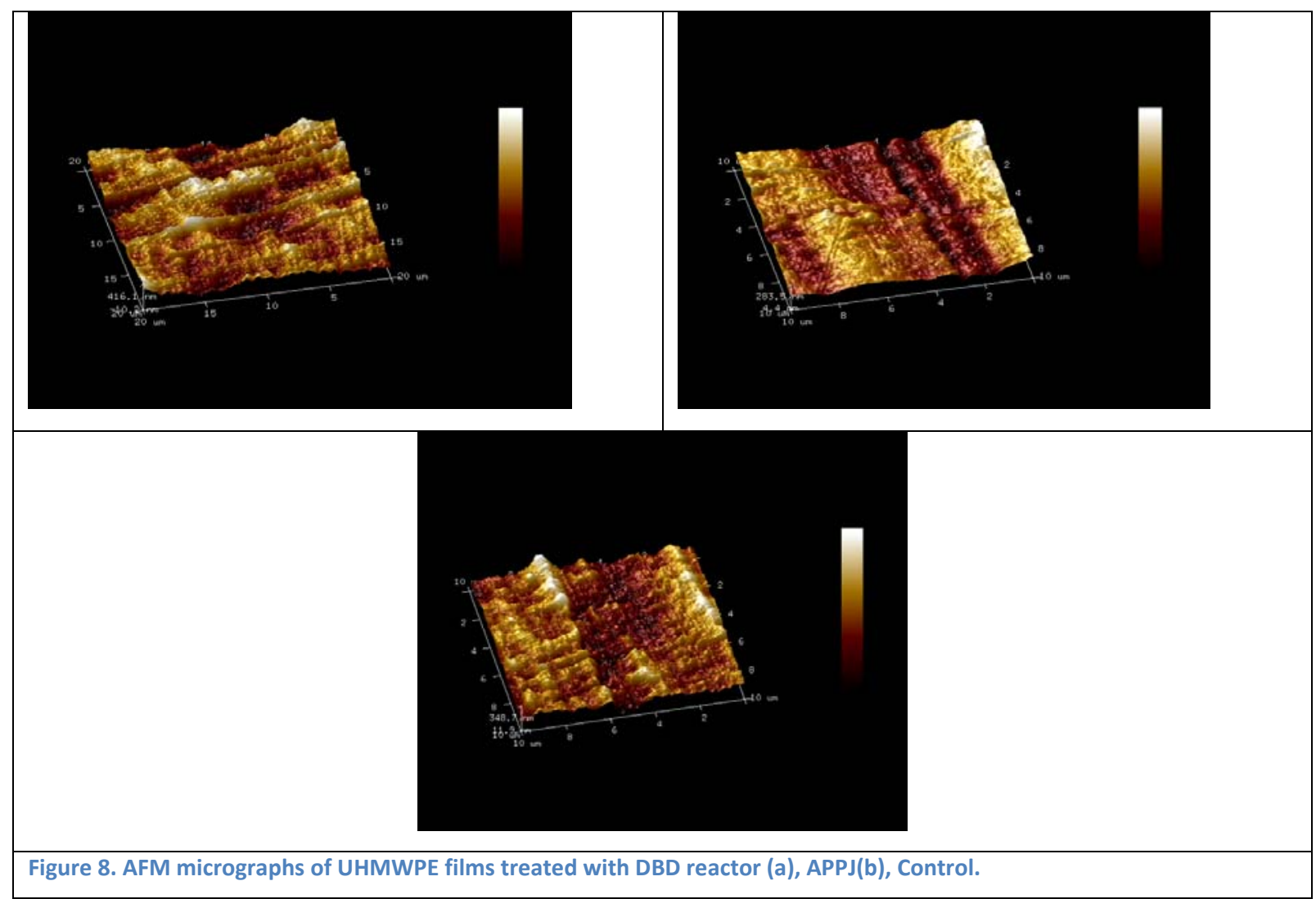

Table 4. Variation of the arithmetical and RMS roughness measured by AFM analysis after 5 min plasma treatment by DBD reactor and APPJ.

\begin{tabular}{|l|c|c|}
\hline Sample & $\mathbf{R}_{\mathbf{q}}(\mathbf{n m})$ & $\mathbf{R}_{\mathbf{a}}(\mathbf{n m})$ \\
\hline Control & 94.4 & 74.7 \\
\hline
\end{tabular}




\begin{tabular}{|l|c|c|}
\hline APPJ & 81.7 & 66.9 \\
\hline DBD & 115 & 90.3 \\
\hline
\end{tabular}

Even though we can observe as compared to the nontreated polymer a slight smoothening of the UHMPE due to the APPJ and a small increase of the roughness in the case of the DBD treatedsamples, these changes are not significant as compared to the arithmetical roughness) and RMS roughness of the nontreated samples $\mathrm{Ra}=74.7 \mathrm{~nm}$ and $\mathrm{Rq}=94.4 \mathrm{~nm}$ respectively.

\subsection{Assessment of plasma activation and SBF incubation of UHMWPE}

As explained in section 3.2 calcium apatite layers formed on the polymer surface immersed in SBF solution can be a good way to determine the extent of bioactivity improvement of the treated UHMWPE surface. To this end, the air and He/O plasma treated samples after different times of immersion in SBF were analyzed by SEM. Calcium apatite formation on APPJ-treated and DBDtreated UHMWPE films are shown in the SEM micrographs in figure 9. 


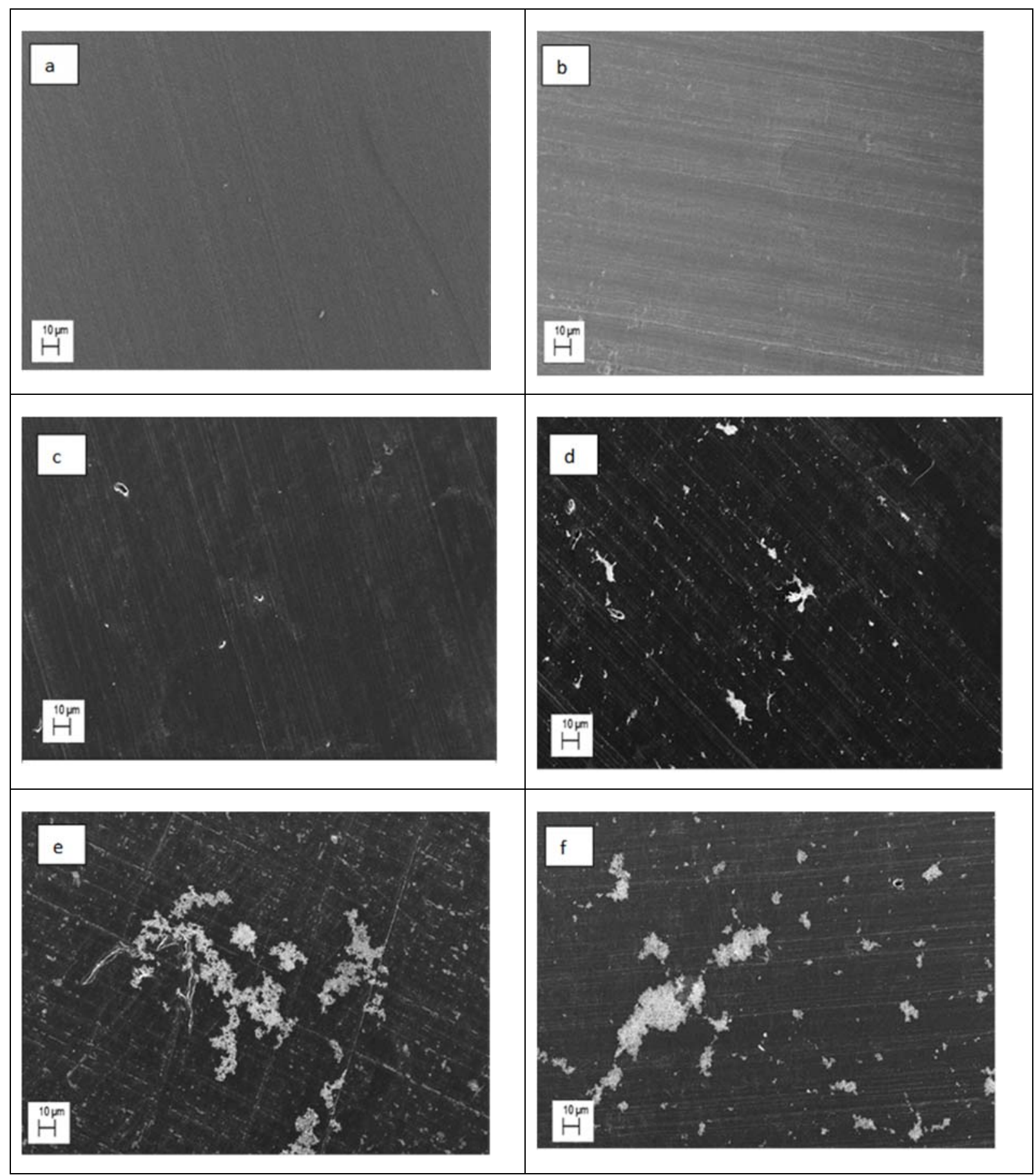

Figure9 :SEM micrographs of HA particle morphologies on UHMWPE substrates after 1 day(left) and 3 days immersion (right)in SBF having undergone no pretreatment $(a, b)$, rotative APPJ treatment in $(c, d)$, DBD treatment $(e, f)$

In the case of the DBD treated UHMWPE film which was immersed in SBF for up to 30 days, an apatite layer was first formed on its surface on day 1, while for APPJ treated films this period was extended to 3 days. The underlying structures of the particles are several spherical particles 
with a diameter of $25.0 \mathrm{~nm}( \pm 8.35 \mathrm{~nm})$ clustered together. The clustering of the spherical particles gives the impression of an elongated structure. The dimensions of the elongated clusters were $140.0 * 96.9 \mathrm{~nm}( \pm 20.8 \mathrm{~nm} * \pm 10.3 \mathrm{~nm})$, as determined by digital image analysis.

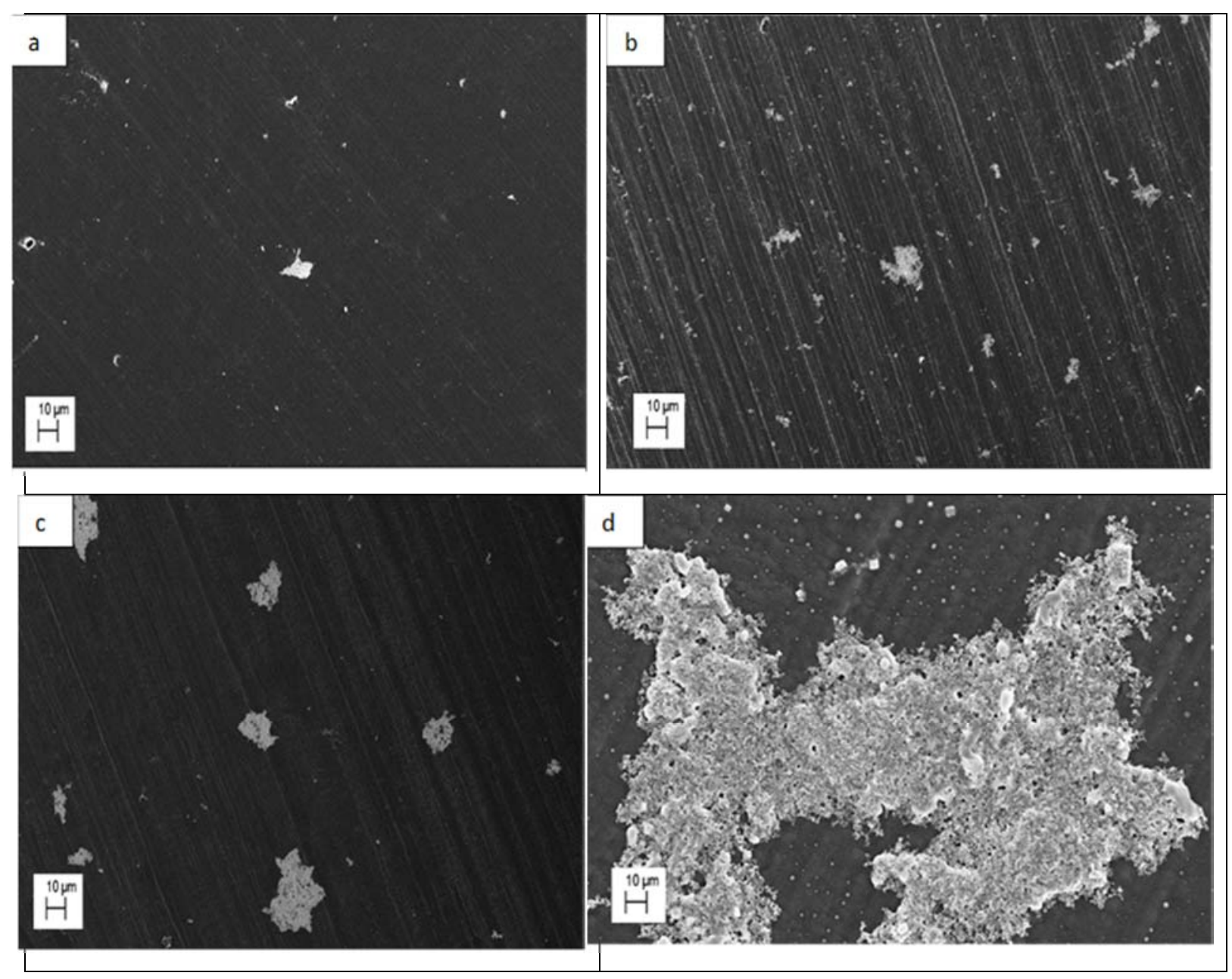




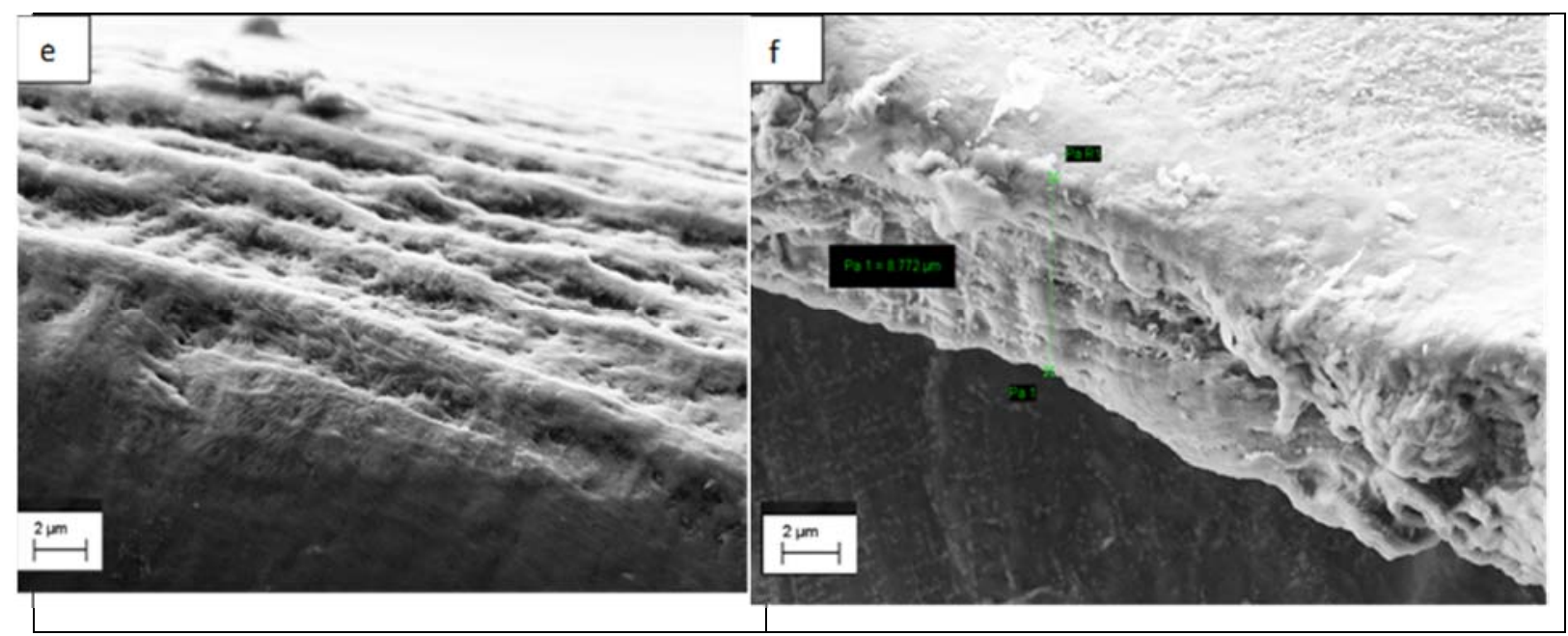

Figure 10 : SEM micrographs of HA particle morphologies on UHMWPE substrates after 7 (left) and 14 days immersion (right)in SBF having undergone no pretreatment $(a, b)$, rotative APPJ treatment in $(c, d)$, DBD treatment $(e, f)$

We can observe clearly a faster kinetics of nucleation and growth of HA on DBD- treatedUHMWPE film and the formation of a $8 \mu \mathrm{m}$ thick HA continuous layer on the surface after 14 days.

For all pretreated films immersion in SBF initially resulted in the formation of a group of agglomerated clusters. By -increasing the immersion time in SBF, further apatite deposition resulted in the growth of these clusters giving rise to a continuous layer (fig 10), becoming thicker and more compact with time consisting of nanoparticles of apatite crystallites, which were characteristic of coatings precipitated from SBF immersion. In contrast, films that were not activated showed a very little amount of calcium apatite particles deposited on the surface even after 14 days in SBF.

As the immersion time progresses, additional nucleation and growth occurred producing a more consolidated apatite layer (Fig 10). After 14 days the DBD treated samples were completely covered by an apatite layer followed by a second layer above the initial compact layer.

These results are in agreement with previous results reported in the literature [13][14] where the authors found that the plasma activation by a mixture of helium and oxygen gases in a DBD reactor provides more favorable sites for nucleation and growth of apatite.

To summarize, faster and larger apatite depositions were observed on the DBD treated surface, compared to APPJ treated samples. This proved that the DBD treatment is a more efficient way 
to graft more functional groups on the UHMWPE surface [16], leading to a more hydrophilic surface which resulted in an increase the rate of HA deposition on its surface from SBF.

Besides SEM analysis, $\mathrm{X}$-ray diffraction analysis has been carried out on HA coatings, and the results have been shown in Figure 11 for untreated and DBD -plasma treated UHMWPE samples after 3 days of immersion in SBF. Other XRD patterns have not been depicted as they are very similar to the ones presented in Fig. 11. The HA peaks appeared in DBD treated sample at $2 \theta$ values of $11^{\circ}-32^{\circ}$ proving the deposition of crystalline structure of hexagonal HA . All samples display different polyethylene crystalline phases and the dominant peaks at, $21^{\circ}$ and $24^{\circ}$ are attributed to the orthorhombic (110) and orthorhombic (200) planes respectively.

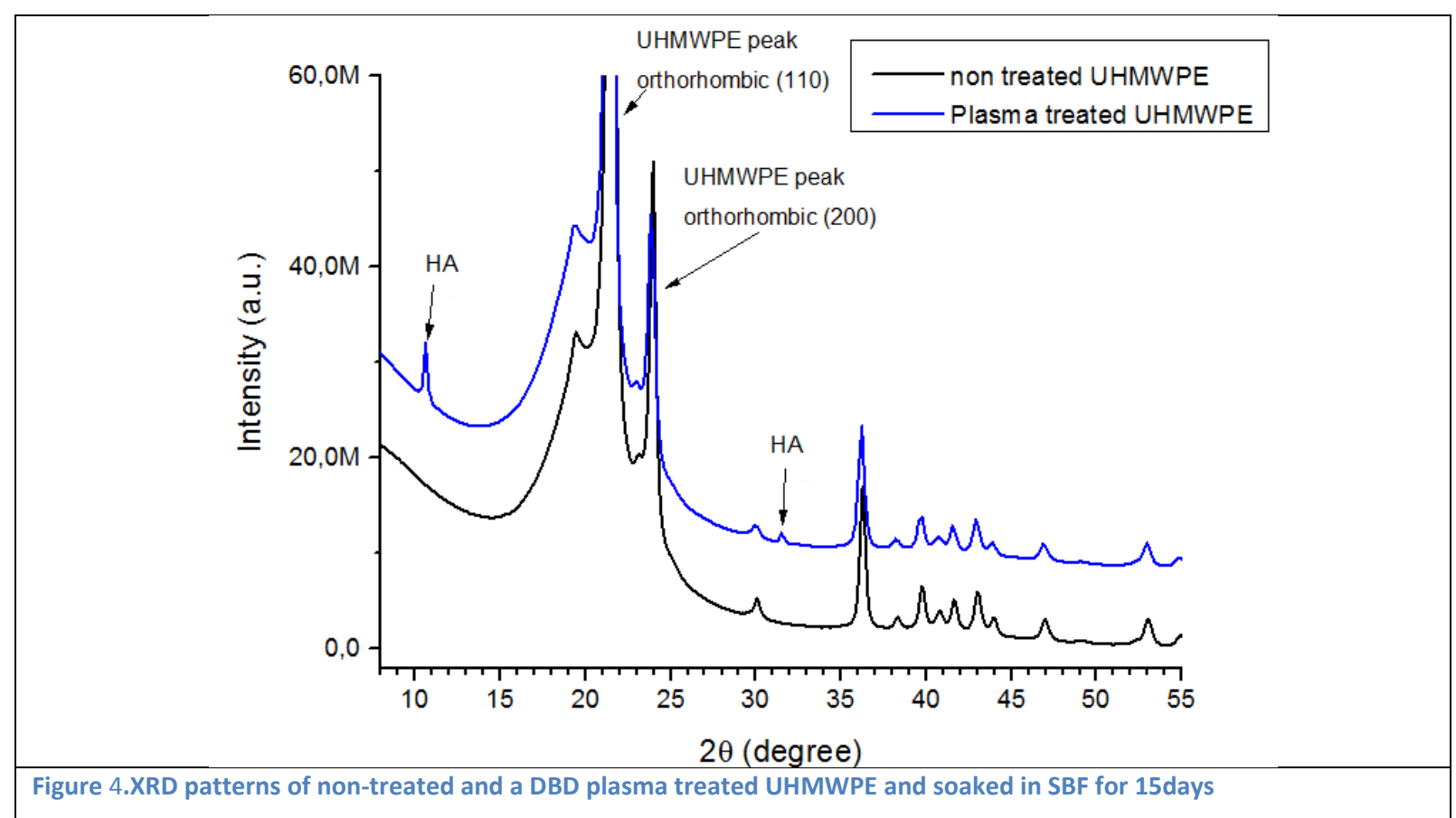

\subsection{Cell adhesion on plasma activated UHMWPE}

In order to determine the biocompatibility of our surfaces, plasma-treated UHMWPE as well as untreated ones were put in contact with fibroblast cells which were cultured in a DMEM medium for 3 days. The adhesion of fibroblast cells were examined in-vitro by putting the cells with the media in contact with the surfaces up to 3 days. The results show that the cells adhered and grew 
on activated film surfaces whereas no cells attached on the surface of the control films(nontreated) at the end of the $3^{\text {rd }}$ day.
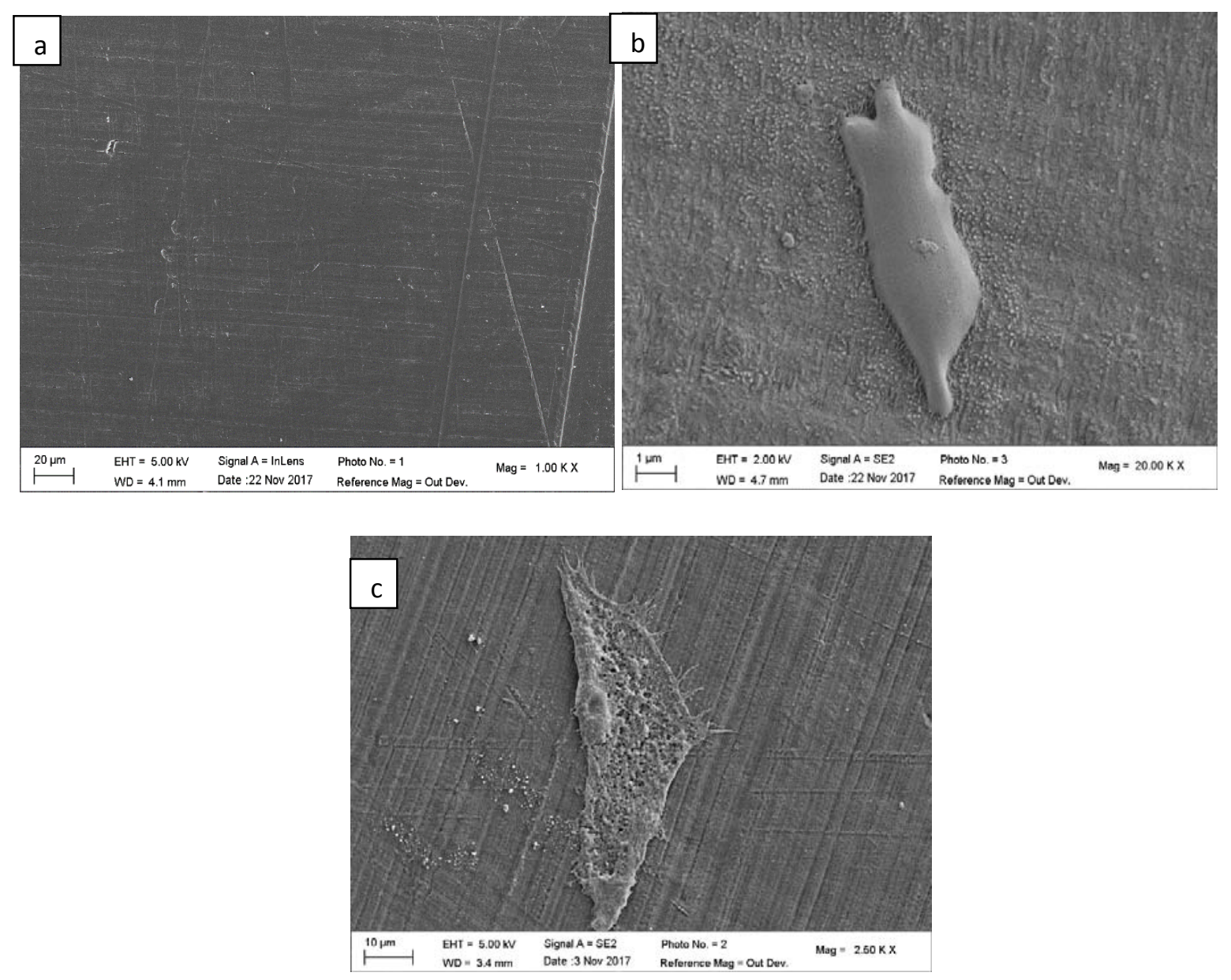

Figure12.Photographs of fibroblast adhered cells onto UHMWPE after 72 hours, a) no pretreatment (b), treated by rotative APPJ in air (c), treated by DBD in $\mathrm{He} / \mathrm{O}_{2}(2 \%)$

SEM was used to determine the morphology of the attached fibroblasts on the APPJ and DBD activated UHMWPE specimens, after $72 \mathrm{~h}$ cell seeding. Fig. 12 reveals no fibroblasts on the untreated UHMWPE after incubation for $72 \mathrm{~h}$. In contrast, after the same incubation period, fibroblast cells spread and proliferated on the plasma modified surfaces. Fibroblasts which spread on the surface of DBD-treated UHMWPE and were attached by means of filopodes showed a clear better biocompatibility as compared to the APPJtreated ones. Indeed some cells were attached onto the surface of the latter but the cells seemed to attach less to the surface and more to themselves on such surfaces. Furthermore these attached cells to the surfaces occupied a much smaller surface (Fig. 12.b) as compared to the DBD-treated ones(Fig.12.c) The cells seeded on surfaces containing higher concentrations of carboxylic acid groups (DBD ones) show a 
better cell spreading with distinctive filopodia formed by the actin skeleton. In contrast, in the case of APPJ-treated surface, the cells show a lower affinity, maintaining a rounder shape.

These differences could be explained by the fact that the type of functional groups played an important role, in other words, although the same type of oxygen bearing groups where detected on DBD and APPJ treated surfaces, and that the surface energy of UHMWPE increase substantially by the two discharges, however in the case of the APPJ discharge, the presence of nitrite/nitrate groups could play a negative role on the adhesion and growth of cells on the surface. Indeed, it has been reported in the literature that Nitric oxide (NOx), a potentially toxic molecule, has been implicated in a wide range of diverse (patho)physiological processes. Cytotoxicity as a result of a massive NOx-formation is now established to initiate apoptosis[35]

\section{Conclusion}

According to the results of this paper He DBD activation of UHMWPE can render these chemically inert surfaces bioactive, making them potential materials integrable in artificial implants. The favorable effect of plasma activation on apatite formation on samples in both treatment methods may at least partly be attributed to an increased wettability of UHMWPE films after DBD and APPJ plasma treatments. Furthermore new heteroatom functional groups grafted on the surface will act as nucleation sites for the adsorption of bioactive HA when immersed in a SBF solution. FTIR and XPS analysis determined more oxygen containing functional groups on DBD treated surface while on APPJ-treated surface NO2/NO3 functional groups were present.

On the other hand it was observed that APPJ-treated surface was more hydrophilic as compared to DBD treated surface. However, the former-treated surfaces with a blown arc in air were less stable with time (shown by CA measurements) as compared to the DBD treatment in mixtures of He/O2. Indeed ATR-FTIR and XPS analyses showed a more reinforced and crosslinked surface in the case of DBD treated one in helium as compared to the APPJ treated one.

Furthermore a fast nucleation and growth of a homogeneous thick carpet layer of HA in the case of DBD treated polymers was observed on which different oxygen bearing groups i.e. hydroxyl, carbonyl and carboxylic groups were detected. Such surfaces showed also to be cytocompatible 
by measuring in-vitro the cell adhesion to fibroblast cells. On the contrary the APPJ-treated UHMWPE, showed to be a less bioactive surface. Indeed, although such plasma-treated surfaces were more hydrophilic, they gave rise I to less bioactive surfaces probably because of grafting less oxygen containing groups to the surface but probably due to particular functional groups such as NO2/NO3 observed on the surface by XPS which were not favorable for cell adhesion. The difference between the DBD-plasma-treated surface and APPJ-treated UHMWPE ones in terms of the resulting bioactivity properties, could not be explained by change of the roughness of the coatings since AFM analysis showed that neither of the two activation methods made significant changes on the surface roughness as compared to the untreated UHMWPE.

XRD analyses performed on the HA-covered samples showed a hexagonal crystalline structure corresponding to HA.

In conclusion this research work has clearly shown that the DBD-treated UHMWPE in a mixture of $\mathrm{He} / 2 \% \mathrm{O} 2$ allows to modify the surface properties of UHMWPE to obtain a bioactive surface without affecting the cytocompatibility and allowing to obtain a well spread homogeneous layer of fibroblast cells after $72 \mathrm{~h}$.

\section{References}

[1] J. Lai et al., 'Study on hydrophilicity of polymer surfaces improved by plasma treatment', Appl. Surf. Sci., vol. 252, no. 10, pp. 3375-3379, 2006.

[2] S. M.KURTZ, UHMWPE BIOMATERILAS HANDBOOK, Second. Philadelphia,PA, 2009.

[3] Z. Gao, J. Sun, S. Peng, L. Yao, and Y. Qiu, 'Surface modification of a polyamide 6 film by He/CF4 plasma using atmospheric pressure plasma jet', Appl. Surf. Sci., vol. 256, no. 5, pp. 1496-1501, 2009.

[4] S. F. E, L. Shi, Z. G. Guo, and W. M. Liu, 'The recent progress of tribological biomaterials', Biosurface and Biotribology, vol. 1, no. 2, pp. 81-97, 2015.

[5] A. Valinataj Omran, A. Baitukha, J. Pulpytel, F. Sohbatzadeh, and F. Arefi-Khonsari, 'Atmospheric pressure surface modification and cross-linking of UHMWPE film and inside HDPE tube by transporting discharge', Plasma Process. Polym., vol. 15, no. 1, pp. 1-12, 2018. 
[6] P. Slepička, S. Trostová, N. Slepičková Kasálková, Z. Kolská, P. Sajdl, and V. Švorčík, 'Surface modification of biopolymers by argon plasma and thermal treatment', Plasma Process. Polym., vol. 9, no. 2, pp. 197-206, 2012.

[7] S. Tajima and K. Komvopoulos, 'Surface modification of low-density polyethylene by inductively coupled argon plasma', J. Phys. Chem. B, vol. 109, no. 37, pp. 17623-17629, 2005.

[8] S. Perni, M. G. Kong, and P. Prokopovich, 'Cold atmospheric pressure gas plasma enhances the wear performance of ultra-high molecular weight polyethylene', Acta Biomater., vol. 8, no. 3, pp. 1357-1365, 2012.

[9] C. M. Klapperich, L. A. Pruitt, and K. Komvopoulos, 'Chemical and biological characteristics of low-temperature plasma treated ultra-high molecular weight polyethylene for biomedical applications.', J. Mater. Sci. Mater. Med., vol. 12, no. 6, pp. 549-56, 2001.

[10] J. L. Audic, F. Poncin-Epaillard, D. Reyx, and J. C. Brosse, 'Cold plasma surface modification of conventionally and nonconventionally plasticized poly(vinyl chloride)-based flexible films: Global and specific migration of additives into isooctane', J. Appl. Polym. Sci., vol. 79, no. 8, pp. 1384-1393, 2001.

[11] G. Borcia, A. Chiper, and I. Rusu, 'Using a $\mathrm{He}+\mathrm{N}_{2}$ dielectric barrier discharge for the modification of polymer surface properties', Plasma Sources Sci. Technol., vol. 15, no. 4, pp. 849-857, 2006.

[12] E. C. Preedy, E. Brousseau, S. L. Evans, S. Perni, and P. Prokopovich, 'Adhesive forces and surface properties of cold gas plasma treated UHMWPE', Colloids Surfaces A Physicochem. Eng. Asp., vol. 460, pp. 83-89, 2014.

[13] P. Cools, S. Van Vrekhem, N. De Geyter, and R. Morent, 'The use of DBD plasma treatment and polymerization for the enhancement of biomedical UHMWPE', Thin Solid Films, vol. 572, pp. 251-259, 2014.

[14] S. Van Vrekhem et al., 'Application of atmospheric pressure plasma on polyethylene for increased prosthesis adhesion', Thin Solid Films, vol. 596, pp. 256-263, 2015.

[15] M. Kawashita et al., 'Apatite-forming ability of carboxyl group-containing polymer gels in a simulated body fluid', Biomaterials, vol. 24, no. 14, pp. 2477-2484, 2003.

[16] K. C. Baker, J. Drelich, I. Miskioglu, R. Israel, and H. N. Herkowitz, 'Effect of polyethylene pretreatments on the biomimetic deposition and adhesion of calcium phosphate films', Acta Biomater., vol. 3, no. 3 SPEC. ISS., pp. 391-401, 2007.

[17] N. De Geyter, R. Morent, and C. Leys, 'Surface characterization of plasma-modified polyethylene by contact angle experiments and ATR-FTIR spectroscopy', no. August 2007, pp. 608-611, 2008.

[18] S. Perni, M. G. Kong, and P. Prokopovich, 'Cold atmospheric pressure gas plasma enhances 
the wear performance of ultra-high molecular weight polyethylene', Acta Biomater., vol. 8, no. 3, pp. 1357-1365, 2012.

[19] T. Kokubo and H. Takadama, 'How useful is SBF in predicting in vivo bone bioactivity?', Biomaterials, vol. 27, no. 15, pp. 2907-2915, 2006.

[20] T. Kokubo et al., 'Ca, P-rich layer formed on high-strength bioactive glass-ceramic A-W', J. Biomed. Mater. Res., vol. 24, no. 3, pp. 331-343, 1990.

[21] J. Huang, L. Di Silvio, M. Wang, I. Rehman, C. Ohtsuki, and W. Bonfield, 'Evaluation of in vitro bioactivity and biocompatibility of Bioglass??-reinforced polyethylene composite', J. Mater. Sci. Mater. Med., vol. 8, no. 12, pp. 809-813, 1997.

[22] M. Tanahashi and T. Matsuda, 'Surface functional group dependence on apatite formation on self-assembled monolayers in a simulated body fluid.', J. Biomed. Mater. Res., vol. 34, no. 3, pp. 305-315, 1997.

[23] A. Oyane, M. Uchida, C. Choong, J. Triffitt, J. Jones, and A. Ito, 'Simple surface modification of poly ( $\varepsilon$-caprolactone) for apatite deposition from simulated body fluid', Biomaterials, vol. 26, no. 15, pp. 2407-2413, 2005.

[24] A. C. Guastaldi, 'Biomimetic apatite formation on Ultra-High Molecular Weight Polyethylene ( UHMWPE ) using modified biomimetic solution', pp. 1215-1222, 2009.

[25] T. Kokubo, 'Formation of biologically active bone-like apatite on metals and polymers by a biomimetic process', Thermochim. Acta, vol. 280-281, no. SPEC. ISS., pp. 479-490, 1996.

[26] M. Desbois, S. J. Cook, and S. W. Emmons, 'High strength and bioactive hydroxyapatite nano-particles reinforced ultrahigh molecular weight polyethylene Liming', no. 852, pp. 18, 1879.

[27] M. Pino, 'Apatite Deposition on NaOH-treated HDPE, PEEK and UHMWPE films for Sclera Materials in Artificial Cornea Implants', 2010.

[28] A. Martins et al., 'Surface modification of electrospun polycaprolactone nanofiber meshes by plasma treatment to enhance biological performance', Small, vol. 5, no. 10, pp. 11951206, 2009.

[29] P. Cools, H. Declercq, N. De Geyter, and R. Morent, 'A stability study of plasma polymerized acrylic acid films', Appl. Surf. Sci., 2017.

[30] A. Reznickova, Z. Novotna, Z. Kolska, N. Slepickova, S. Rimpelova, and V. Svorcik, 'Enhanced adherence of mouse fi broblast and vascular cells to plasma modi fi ed polyethylene', vol. 52, pp. 259-266, 2015.

[31] B. K. Kim, K. S. Kim, K. Cho, and C. E. Park, 'Retardation of the surface rearrangement of $\mathrm{O} 2$ plasma-treated LDPE by a two-step temperature control', J. Adhes. Sci. Technol., vol. 15, no. 14, pp. 1805-1816, 2001. 
[32] H. J. Gengenbach, T. R., \& Griesser, 'Post-deposition ageing reactions differ markedly between plasma polymers deposited from siloxane and silazane monomers', Polymer (Guildf)., vol. 40, no. 18, pp. 5079-5094, 1999.

[33] M. E. Mora, M. A., Auman, H. J., Ludwig, J. P., Giesy, J. P., Verbrugge, D. A., \& Ludwig, 'Polychlorinated biphenyls and chlorinated insecticides in plasma of Caspian terns: relationships with age, productivity, and colony site tenacity in the Great Lakes', Arch. Environ. Contam. Toxicol., vol. 24, no. 3, pp. 320-331, 1993.

[34] Massines, F., Sarra-Bournet, C., Fanelli, F., Naudé, N. \& Gherardi, N. Atmospheric pressure low temperature direct plasma technology: status and challenges for thin film deposition. Plasma Processes and Polymers 9, 1041-1073 (2012).

[35] B. Brüne B, K. Sandau, A. von Knethen, Nitric oxide (NO): an effector of apoptosis., Cell Death Differ. 1999 Oct;6(10):969-75.

[36] J. A. Jofre-Reche, J. Pulpytel, H. Fakhouri, F. Arefi-Khonsari, J. M. Martin-Martinez, Surface Treatment of Polydimethylsiloxane (PDMS) with Atmospheric Pressure Rotating Plasma Jet. Modeling and Optimization of the Surface Treatment Conditions, Plasma Process. Polym. 2016, 13, 459.

[37] J. Pulpytel, V. Kumar, P. Peng, V. Micheli, N. Laidani, F. Arefi- Khonsari, Deposition of organosilicon coatings by a non-equilibrium atmospheric pressure plasma jet : design, analysis and macroscopic scaling law of the process, Plasma Process. Polym. 2011, 8,664 . 